\title{
Bookselling Among the Sciences
}

By JAKE ZEITLIN

$\mathrm{T}$ HE COLlector CERTAinly is the one who leads the tune for both the bookseller and the librarian. His fertility and independence of mind brings fresh ideas into the book world, and I should not forbear to speak of the fresh money he introduces into a trade noted for it's internal commerce. His new enthusiasms send us back into our bins and cellars. He often turns our previously unsold stock into gold. The librarian depends upon the private collector, not only for gifts, but even more for the standards of merit and the standards of value upon which he is able to justify the maintenance and development of a rare book collection. The magical effect on a tightfisted administration of the example of a successful business or professional man, who has spent generous sums of money on rare books, is highly tonic.

It is my task, however, to say something about the rise of the history of science as a subject of importance both to scholarship and book collecting. I am also to name some of the notable collectors. And finally, I intend to take advantage of this occasion to recount the role that antiquarian booksellers have played in the cultivation and encouragement of collectors and librarians.

Much of what I have to say has been inspired, and some of it has been shamelessly lifted from the address of my venerable colleague, Dr. Ernest Weil, entitled: "Milestones of Civilization." It was delivered under the auspices of the Antiquarian Booksellers Association of London in 1948. Dr. Weil said, "The history of science ... is a child of our generation and consequently the collection of books illustrating the history of
$\mathrm{Mr}$. Zeitlin is president of Zeitlin \& Ver Brugge, Booksellers, Los Angeles. These remarks, slightly revised, were made at a meeting of ACRL's Rare Books Section, Montreal, June 20, 1960.

science is a recent development."

Before proceeding I should like to differentiate between the collecting of magnificently illustrated works of natural history (such as the folios of Audubon and the array of Gould's brilliantly colored works on birds, the flower plate books of Redoute and Thornton), and the collecting of works illustrating the history of science. Natural history is often the logical predecessor of science, but there is little correspondence between the taste for graphic beauty and the taste which can pride itself in the possession of Harvey's De Motu Cordis, or Kepler's Harmonicas Mundi; both books which are notorious for their miserable discoloration and bad typography. The difference goes deeper than appearances; it reflects the growth of the concept that description and classification are merely the prelude to science, and that the stuff of science is the disciplined development of ideas about our universe, both great and small, how it works, its relationship to the mind of man and how it will determine what is to become of the human race.

The development of interest in certain specialties is associated with the publication of certain notable bibliographies or histories. In medicine we may cite Choulant's Handbuch and his Bibliography and History of Anatomic Illustra- 
tion. In chemistry, Ferguson's Bibliotheca-Chemica which served as a beacon and a pilot for such recent publications as Denis Duveen's Bibliotheca ChemicaAlchemica. In electricity, Mottelay's Bibliography \& History, and more recently The Wheeler Gift Catalogue, have served us well. The bibliographic writings of Sylvanus Thompson on William Gilbert are the forerunners of the beloved Dr. John Fulton's bibliographies of Boyle, Mayow, and Galvani, and of Geoffrey Keynes' admirable models of bibliographical descriptions on William Harvey and Thomas Browne.

The foundations were also laid by such pioneer histories as Cantor's and Montucla's in mathematics; Bailly's in Astronomy; Sprengel's and Garrison's in medicine, and Paul Tannery's in classical science.

But what has emerged in our time is a greater insight, illuminated by historical research, into the effect that the speculations of the mathematicians and the experimenters with kites, crystals and cyclotrons and the influence they have had, and will in the future have, on what will become of us all. This began to manifest itself in such works as Lynn Thorndike's History of Magic and Experimental Science; Martha Orenstein's The Role of Scientific Societies in the Seventeenth Century, and became explicit with George Sarton's publication of his monumental Introduction to the History of Science. Sarton's devotion to this subject and his publication of the journal Isis have been most influential throughout the world of learning.

Now we have the first publication of a work devoted exclusively to our field of discussion: Thornton \& Tully's Scientific Books, Libraries And Collectors: A Study of Bibliography and the Book Trade (London: 1954). Despite an embarrassing plenitude of errors and omissions, which I do not doubt will be corrected in a second edition, it is a most comprehensive and scholarly survey from ancient times to today. The chapters on scientific bibliographies, private scientific libraries, and scientific publishing and bookselling are a necessary supplement to what we have to say here today. Also it is very pleasant reading.

Most practicing scientists have insisted that science has no moral commitments. As a corollary, most members of the scientific faculties of our universities have taken the position that the working scientist has no need for a knowledge of the history of science. Some years ago Dr. Robert Oppenheimer voiced this opinion to me when I delivered the first of the several great collections, formed by that Nestor of scientific bibliomania, Dr. Herbert Evans, and presented by Lessing J. Rosenwald, to the Institute for Advanced Study. He named Dirac as an example of the scientific thinker whose works have no roots in the past. In justice to Dr. Oppenheimer I must record that he has since revised his views. The only concern with the history of science some of our scientists have exhibited has to do with making certain that their particular contribution shall have its share, or more, of credit in the records. One might say that their interest is more eponymical than historical.

As in many other fields the pioneering has been done by the amateurs and the broadly based humanistic historians. We are now entering a period of intensive development with the establishment of departments or professorships, not only at Harvard where Sarton and Dr. I Bernard Cohen have long carried the torch, but also at Cornell, Princeton, Yale, Wisconsin, Oklahoma, Kansas and California, with Illinois and several other universities soon to follow. There are few challengers to Herbert Butterfield's statement in his Horblit Lecture at Harvard, where he said, "For some of us the history of science is likely to be the only gateway to any knowledge of scientific ideas, and the only key to the deeper and the underlying structure of the sciences." 
Recently Dr. James Conant, also a Horblit lecturer, delivered a stirring address on the need for scientists to be aware of the history of science in the larger role that many of them are playing in shaping national policy. But he also echoed the doubts of his colleagues as to the applied value for the working scientist. Some scientists are still operating as if they were sealed into a space capsule; they know what they are doing but they don't know where they are going. Charles Gillespie has given the answer better than anyone else I know: "It . . . [meaning particularly the consciousness of the effect of Newton's Principia] . . . is an element of culture and to exist in a culture with no notion whence it came is to invite the anthropologists' inquiry rather than to live as an educated man, aware and in that measure free.".

Two outstanding exhibitions have done much to enrich and extend the interest of both scientists and book collectors. In 1934, Dr. Evans prepared an exhibition of "Landmarks in the History of Science" for the meeting of the American Association for the Advancement of Science, held in Berkeley. Fortunately the catalog of that exhibition was published by the University of California Press and has served to inspire many a subsequent collection. Likewise, the great exhibition of "Classics in the History of Science" opened at the Grolier Club in February of 1958 with a brilliant address by Dr. Cohen, did much to broaden the horizon of many bookmen, and regretfully, to raise the prices of many neglected books. I hope Harrison Horblit's zealous editing of the catalog of this exhibition will not prevent it from being released soon.

Bern Dibner has added considerable fuel to the fire of scientific bookcollecting with the publishing of his Heralds of Science. It is a selection from his library of the two hundred titles which have in a greater or lesser degree heralded the introduction of some impor- tant idea or discovery. I am not a modest man, so I will quote his dedication. It reads, "To the book-dealers in many lands who patiently gathered, preserved, collated and cataloged our heritage of science, and who in their transactions invariably gave away more than they received." Now that is the kind of appreciation we like to hear.

Here in Montreal we are in close proximity to two world-renowned examples of the specialized historical library gathered by dedicated book collectors and retained intact for the use of scholars. Wherever the history of medicine is pursued one essential reference is Bibliotheca Osleriana compiled by the much beloved Dr. W. W. Francis. Not only is it a highly individualized catalog of the medical treasures of the great Sir William, but it is also delightfully animated with the record of his unrepentent bibliophily. Equally important, but somewhat less celebrated, is the Blacker Collection of Vertebrate Zoology. It was gathered with the generous support of Mr. and Mrs. Robert Roe Blacker, and the enterprise of one of Dr. Osler's friends, Dr. Casey Wood, from all quarters of the globe. The catalog of this collection might be called the bosom book of all zoologically-minded bibliophiles. I cannot refrain from boasting that my copy bears an inscription from both Dr. Wood and Mrs. Blacker.

These are a few instances of how much has been done by private book collectors with the enthusiasm, the means and the freedom from administrative restraints. Everette De Golyer once said to me, "Sell me the expensive books, it's my money I'm spending that I can indulge myself as no librarian will have the guts to do after I'm gone." Science collectors of the past and present, like Osler, and Blacker, Cushing, Klebs and Fulton, Ralph Ellis, LeRoy Crummer, Herbert Evans, Harrison Horblit, Robert Honeyman, Albert Lownes and our friend Bern Dibner, to name a few, are the ones fortunate 
enough to create such highly individualised and useful monuments to their personal taste. The great Leonardo collection of Dr. Elmer Belt, soon to become the property of the University of California, is an illustrious example of this spirit and I am proud to have assisted in its creation.

The collecting of rare editions of the classics of science has come under the same questioning as has the collecting of first and rare editions of literary classics. "Why," asks the uninformed person, "can't we just depend upon reprints or the latest editions?" "Why do we have to spend large sums of money on the first or early edition?" Fortunately the growth of descriptive bibliography, the development of a new method of textual research has conclusively proved the unreliability of scholarship based on facsimiles and current editions alone. The labors of McKerrow, Greg, Todd, Bowers, and others are now bearing fruit in fields other than literature. A re-examination of the texts of Galileo, for instance, may be the basis for revising our notions of what he did at the tower of Pisa.

What have we booksellers had to do with all of this? First and foremost, we have aided in the rescuing and preserving of much material that might otherwise have gone into the fireplace or the pulp mill. Second, we have served as the conveyor belt in the process of distributing and collecting. Third, we have through our cataloging and pricing assisted in the proper evaluation of materials with respect to both importance and rarity. And finally, the bibliographically inclined among us have sometimes made contributions to the knowledge of the whereabouts and textual importance of many items that otherwise might be overlooked. The shelves of booksellers' catalogs, which usually stand close to the desks of collectors, scholars and librarians, are one of the best testimonies of our usefulness.
A bookseller's catalogs are his showcase. They often represent the fruit of many years of keeping back his choicest books as well as many hours of research. He stakes his livelihood and reputation upon the statements he makes. The catalogs of Dr. Ernest Weil for years set a high standard of scholarly notes for us all, as have those of Herbert Reichner and Irving Davis. Among the pioneer landmarks is the erudite series entitled, Biliotheca Physico-Mathematica, compiled by Henry Zeitlinger for Henry Sotheran. What mouth-watering plums they describe. Any of us would gladly buy the contents of the whole catalog if we could find such items again at such prices. Equally high in merit are the catalogs of L'Art Ancien, especially those medical and botanical, and the series of former years from R. Lier. From the top of the Spanish Stairs in Rome have come Rappaport's long series and from the banks of the Arno in Florence Leo Olschki's erudite enticements. Many years ago Dr. Pilcher wrote an enchanting account of how he discovered there, and bore away in triumph, a copy of Berengario di Carpi's Commentary on Mundinus. E. P. Goldschmidt's handsome productions of former years are rich in scholarship as well as treasures no longer to be had, as are several eminent landmarks from Maggs Brothers. Undoubtedly Percy Muir's learned notes in the catalogs of Elkin Mathews have done much in our day to rescue many unappreciated titles from oblivion. Raphael King's several catalogs are still to be consulted for their highly original notes as well as for the regrets they inspire when one sees a Sceptical Chemist, for instance, offered for f 350. And nowadays we have the imposing array of wares offered by William Dawson \& Sons at prices we would not have dared to dream of ten years ago, but which we now eagerly gobble up. From London also come the very worthy catalogs of Hugh K. Elliott, a very 
knowledgeable newcomer to the book trade, I would not want to forget the hours of antiquarian bliss I have enjoyed in the shop and in the pages of the catalogs of A. Bader of the Grand Rue in Geneva.

In the United States the dean among living scientific booksellers is Henry Schuman, probably the first to devote himself exclusively to medicine and science. He pioneered in the field of American medicine and inspired many of us to emulate his example if not his very special brand of humor. The series of books he published have become a permanent part of the bibliography of the history of science and will remain a testament to his ill-repaid courage. All of us have reaped from the harvest that he sowed. David Randall of Scribner's published several notable catalogs. His Science and Thought in the Nineteenth Century is still consulted for its pithy notes and no longer startling prices. Also outstanding in the field of the history of medicine are those catalogs which come from the Old Hickory Bookshop, whose Murray Gottlieb is affectionately remembered, and whose Johanna happily still abides with us.

Thomas Heller's catalogs are models of clear description, well edited notes and reasonable prices. And the catalogs of Emil Offenbacher have brought many a book collector to Kew Gardens in Long Island. Lastly, I should like to mention the catalogs which come from Wolfpits Road, in Bethel, Conn., Richard Wormser's ability to discover and learnedly describe unknown scientific rarities is surpassed only by his passion of abominable puns.

In closing I should like to say that we antiquarian booksellers like to believe that we perform an essential service in the cycle of books from collector to collector and finally to librarian. In view of the decreasing supply it seems to be a diminishing cycle. By and large we strive to perform the function of collaborator as well as vendor and to elevate our knowledge and understanding of the materials we handle to the level of those with whom we deal. Our greatest pride lies in guiding the intelligent collector and librarian towards the achievement of a great library and the scholar towards the sources which will most enrich his works. This we regard as our part, not only in preserving the knowledge of the past, but also in illuminating the way to a more civilized future.

\section{African Interest Inquiry}

The Joint Committee on African Resources, a sub-committee of the Association of Research Libraries' Farmington Plan Committee, is gathering data concerning: (1) the interest, among American libraries, in obtaining material from Africa (irrespective of Farmington Plan assignments), (2) the interest in extending Farmington Plan allocations to more libraries, since the huge area that must be covered requires increased participation to be effective, and (3) methods of obtaining material from the bibliographically under-developed areas of Africa.

A questionnaire for obtaining such data has been sent to all libraries that hold membership in the Association of Research Libraries or participate in the Farmington Plan, as well as to other libraries assumed to have an interest in material published in Africa. Any library that has not received a copy of the questionnaire but would like one, may obtain a copy by writing to the chairman of the Joint Committee on African Resources, Jens Nyholm, Northwestern University Library, Evanston, Illinois. 